\title{
Iterative method for solving one-dimensional fractional mathematical physics model via quarter-sweep and PAOR
}

\author{
Andang Sunarto ${ }^{1 *}$ (D), Praveen Agarwal ${ }^{2,3}$, Jumat Sulaimann ${ }^{4}$, Jackel Vui Lung Chew ${ }^{5}$ and \\ Elayaraja Aruchunan ${ }^{6}$
}

\author{
${ }^{*}$ Correspondence: \\ andang99@gmail.com \\ 'Department Tadris Matematika, \\ IAIN Bengkulu, Bengkulu City, \\ Bengkulu, 65144, Indonesia \\ Full list of author information is \\ available at the end of the article
}

\begin{abstract}
This paper will solve one of the fractional mathematical physics models, a one-dimensional time-fractional differential equation, by utilizing the second-order quarter-sweep finite-difference scheme and the preconditioned accelerated over-relaxation method. The proposed numerical method offers an efficient solution to the time-fractional differential equation by applying the computational complexity reduction approach by the quarter-sweep technique. The finite-difference approximation equation will be formulated based on the Caputo's time-fractional derivative and quarter-sweep central difference in space. The developed approximation equation generates a linear system on a large scale and has sparse coefficients. With the quarter-sweep technique and the preconditioned iterative method, computing the time-fractional differential equation solutions can be more efficient in terms of the number of iterations and computation time. The quarter-sweep computes a quarter of the total mesh points using the preconditioned iterative method while maintaining the solutions' accuracy. A numerical example will demonstrate the efficiency of the proposed quarter-sweep preconditioned accelerated over-relaxation method against the half-sweep preconditioned accelerated over-relaxation, and the full-sweep preconditioned accelerated over-relaxation methods. The numerical finding showed that the quarter-sweep finite difference scheme and preconditioned accelerated over-relaxation method can serve as an efficient numerical method to solve fractional differential equations.
\end{abstract}

Keywords: Caputo's fractional derivative; Implicit finite-difference scheme; QSPAOR; TFDE

\section{Introduction}

The growing interest in the theory and applications of fractional calculus has become the motivation for many researchers in recent years. Fractional calculus has attracted attention of experts from all over the world. Various fractional operators have been introduced in the literature such as $[3,9-11,27,30,31]$, and this encourages more extensive researches to be conducted. Solving fractional differential equations (FDEs) using numerical methods has been seen as an ongoing research trend. The analytical solutions of most FDEs are

(c) The Author(s) 2021. This article is licensed under a Creative Commons Attribution 4.0 International License, which permits use, sharing, adaptation, distribution and reproduction in any medium or format, as long as you give appropriate credit to the original author(s) and the source, provide a link to the Creative Commons licence, and indicate if changes were made. The images or other third party material in this article are included in the article's Creative Commons licence, unless indicated otherwise in a credit line to the material. If material is not included in the article's Creative Commons licence and your intended use is not permitted by statutory regulation or exceeds the permitted use, you will need to obtain permission directly from the copyright holder. To view a copy of this licence, visit http://creativecommons.org/licenses/by/4.0/. 
challenging compared to the ordinary (ODEs) and partial differential equations (PDEs) in general. Therefore, numerical solutions are actively being found by proposing new numerical approximation techniques to solve the FDEs. Some notable numerical methods have been developed to solve the fractional partial derivatives problems [1, 2, 14, 19, 20, 29].

Besides that, [12] has presented several interesting MATLAB routines for solving FDEs. The author has provided many solution techniques for solving three identified FDE problems such as the standard FDEs, the multiorder systems of FDEs, and the multiterm FDEs. One of the studies [13] presented several computational cost evaluations for the numerical solutions of FDEs from the point of view of computer science. Based on that work, the computational complexities for the time-fractional, space-fractional, and space-time FDEs are known to be $O\left(N^{2} M\right), O\left(N M^{2}\right)$, and $O(N M(M+N))$. The authors have also compared the three mentioned computational costs against $O(M N)$, which is the cost of finding solutions for the classical partial differential equations using finite-difference methods. Here, $M$ and $N$ denote the number of spatial grid points and time steps, respectively. Moreover, the authors have mentioned that the preconditioner technique is a good alternative to accelerate the computational process in solving FDEs.

In our development of the numerical method to solve FDEs, we are interested in applying the second-order quarter-sweep finite-difference scheme with a preconditioning technique to solve the time-fractional FDE (TFDE). There are several finite difference scheme applications to solve the TFDE $[5,7,12,25,26]$. However, the investigation on the efficiency of the numerical method used to solve the TFDE is quite limited. The quartersweep finite-difference scheme has been a good computation complexity reduction approach, especially when a large number of mesh points are considered [4, 22, 28]. The quarter-sweep is able to reduce the computational complexity of computing the solutions of a large linear system by computing a quarter of the total number of mesh points without offsetting the solutions' accuracy. Therefore, this paper investigates the efficiency of the quarter-sweep finite difference scheme with a preconditioning technique called PAOR [26] to solve the TFDE. The PAOR iterative method will be used to compute a quarter of mesh points after quarter-sweep implementation. The remaining mesh points will be estimated by averaging. This efficient numerical method is important to the physicists to aid their investigation on the time-fractional mathematical model, arising from the necessity to sharpen the concepts of equilibrium, stability states, and time evolution in the long time limit $[8,17,18]$.

Throughout this paper, we discretized TFDE using the unconditionally stable secondorder quarter-sweep implicit finite-difference (QSIFD) scheme. We used Caputo's fractional partial derivative to form the approximation equation. Usually, the finite-difference approximation equation's implementation leads to a tridiagonal matrix of the linear system due to its characteristics. The discretized finite-difference approximations also form a large and sparse matrix which is the best alternative to be solved using the iterative method. We have observed the successful iterative methods from many researchers. From many discussions and extensions made in several categories of iterative methods, we find that the preconditioned iterative methods have the unique properties to solve a linear system efficiently $[15,16,23]$.

This paper's main contribution is to present the efficiency of our proposed numerical method, which can be called the quarter-sweep preconditioned accelerated overrelaxation (QSPAOR) iterative method for solving TFDEs. In this paper, the numerical 
method's efficiency is evaluated based on the number of iterations and the computation time. The QSPAOR iterative method's efficiency will be compared against the half-sweep preconditioned accelerated over-relaxation (HSPAOR) and full-sweep preconditioned accelerated over-relaxation (FSPAOR), and the improvement in terms of the reduction of both the number of iterations and computation time will be illustrated. The stability analysis of the quarter-sweep finite difference approximation equation and the AOR iterative method's convergence analysis are also provided.

The general TFDE that we consider as the main problem to be solved can be written as

$$
\frac{\partial^{\alpha} U(x, t)}{\partial^{\alpha} t}=p(x) \frac{\partial^{2} U(x, t)}{\partial x^{2}}+q(x) \frac{\partial U(x, t)}{\partial x}+r(x) U(x, t),
$$

where $p(x), q(x)$, and $r(x)$ are known functions or coefficients; meanwhile, $\alpha$ is a parameter that determines the degree of fractional order for the time derivative. For the formulation of the finite-difference approximation with Caputo's derivative, here are the important definitions that we use:

Definition 1 The Riemann-Liouville fractional integral operator, $J^{\alpha}$, of order- $\alpha$ is defined as

$$
J^{\alpha} f(x)=\frac{1}{\Gamma(\alpha)} \int_{0}^{x}(x-t)^{\alpha} f(t) d t, \quad \alpha>0, x>0
$$

Definition 2 The Caputo's fractional partial derivative operator, $D^{\alpha}$, of order- $\alpha$ is defined as

$$
D^{\alpha} f(x)=\frac{1}{\Gamma(m-\alpha)} \int_{0}^{x} \frac{f^{(m)}(t)}{(x-t)^{\alpha-m+1}} d t, \quad \alpha>0
$$

with $m-1<\alpha \leq m, m \in N$ and $x>0$.

\section{Research methodology}

To solve the fractional differential problem shown in Eq. (1), we assume that the solutions exist and satisfy the Dirichlet boundary conditions. Therefore, using Eq. (2), the timefractional derivative term in Eq. (1) is discretized using

$$
\frac{\partial^{\alpha} u(x, t)}{\partial t^{\alpha}}=\frac{1}{\Gamma(n-1)} \int_{0}^{\infty} \frac{\partial u(x-s)}{\partial t}(t-s)^{-\alpha} d s, \quad t>0,0<\alpha<1 .
$$

Using the approximation equation to Eq. (1) employing the finite-difference method and Caputo's fractional derivative, we develop a $\mathrm{C}++$ code for the simulation of the approximate solutions. We have two examples of the TFDE to examine the iterative methods, i.e., the proposed QSPAOR, HSPAOR, and FSPAOR. The proposed numerical method's efficiency is examined using the number of iterations $(K)$ and the computation time measured in seconds. The maximum absolute error (MAE) is also observed for accuracy checking. These criteria are compared by using three different order parameters $\alpha$, i.e., $\alpha=0.25$, $\alpha=0.50$, and $\alpha=0.75$. The convergence tolerance, $\varepsilon=10^{-10}$, is set to terminate the iteration process. 


\section{Approximation to the time fractional differential equation}

The first-order approximation to the Caputo's fractional derivative, which is derived from the discrete approximation to the time-fractional derivative term shown in Eq. (4), can be written as

$$
D_{t}^{\alpha} U_{i, n} \cong \sigma_{\alpha, k} \sum_{j=1}^{n} \omega_{j}^{(\alpha)}\left(U_{i, n-j+1}-U_{i, n-j}\right),
$$

where, from Eq. (5), we define two representations for the sake of simplicity as follows:

$$
\sigma_{\alpha, k}=\frac{1}{\Gamma(1-\alpha)(1-\alpha) k^{\alpha}},
$$

and

$$
\omega_{j}^{(\alpha)}=j^{1-\alpha}-(j-1)^{1-\alpha}
$$

Then, we use the common discretization by partitioning the solution domain of Eq. (1) uniformly, subjected by the Dirichlet boundary conditions. The numbers $m$ and $n$ ( $m, n \ni$ $\aleph^{+}$) are defined so that the grid framework in space and time is fixed everywhere and has increments denoted as $h=\Delta x=\frac{\gamma-0}{m}$ and $k=\Delta t=\frac{T}{n}$, respectively. Based on the developed uniform grid network, the grid points in the space interval $[0, \gamma]$ are represented by $x_{i}=i$, for $i=0,1,2, \ldots, m$, meanwhile the grid points in the time interval $[0, T]$ are labeled as $t_{j}=j k$ for $j=0,1,2, \ldots, n$. Therefore, the values of the function $U(x, t)$ at the grid points are expressed as $U_{i, j}=U\left(x_{i}, t_{j}\right)$.

The implementation of QSIFD discretization scheme for Eq. (5) produced the Caputo's approximation to Eq. (1) at the grid point $\left(x_{i}, t_{j}\right)=(i h, j k)$ which can be formulated as

$$
\begin{aligned}
& \sigma_{\alpha, k} \sum_{j=4}^{n-4} \omega_{j}^{(\alpha)}\left(U_{i, n-j+1}-U_{i, n-j}\right) \\
& \quad=\frac{p_{i}}{16 h^{2}}\left(U_{i-4, n}-2 U_{i, n}+U_{i+4, n}\right)+\frac{q_{i}}{8 h}\left(U_{i+4, n}-U_{i-4, n}\right)+r_{i} U_{i, n},
\end{aligned}
$$

for $i=4,8, \ldots, m-4$.

When the approximation in Eq. (6) is applied on the specified time level $n \geq 2$, Eq. (6) can be expressed as

$$
\sigma_{\alpha, k} \sum_{j=4}^{n} \omega_{j}^{(\alpha)}\left(U_{i, n-j+1}-U_{i, n-j}\right)=p_{i}^{\prime} U_{i-4, n}+q_{i}^{\prime} U_{i, n}+r_{i}^{\prime} U_{i+4, n}
$$

and the coefficients are represented by

$$
p_{i}^{\prime}=\frac{p_{i}}{16 h^{2}}-\frac{q_{i}}{8 h}, \quad q_{i}^{\prime}=r_{i}-\frac{p_{i}}{8 h^{2}}, \quad r_{i}^{\prime}=\frac{p_{i}}{16 h^{2}}+\frac{q_{i}}{8 h} .
$$

In addition to this, for $n=1$, we have

$$
-p_{i}^{\prime} U_{i-4,1}+q_{i}^{*} U_{i, 1}-r_{i}^{\prime} U_{i+4,1}=f_{i, 1}, \quad i=4,6, \ldots, m-4,
$$

where $\omega_{j}^{(\alpha)}=1, q_{i}^{*}=\sigma_{\alpha, k}-q_{i}^{\prime}$, and $f_{i, 1}=\sigma_{\alpha, k} U_{i, 1}$. 
When a certain number of grid points is considered based on Eq. (8), a system of linear equations is obtained, which can be expressed in the form matrix as follows:

$$
A \underset{\sim}{U}=\underset{\sim}{f}
$$

where

$$
\begin{aligned}
A & =\left[\begin{array}{cccccc}
q_{4}^{*} & -r_{4}^{\prime} & & & & \\
-p_{8}^{\prime} & q_{8}^{*} & -r_{8}^{\prime} & & & \\
& -p_{12}^{\prime} & q_{12}^{*} & -r_{12}^{\prime} & & \\
& & \ddots & \ddots & \ddots & \\
& & & -p_{m-8}^{\prime} & q_{m-8}^{*} & -r_{m-8}^{\prime} \\
& & & & -p_{m-4}^{\prime} & q_{m-4}^{*}
\end{array}\right]_{\left(\left(\frac{m}{4}\right)-1\right) x\left(\left(\frac{m}{4}\right)-1\right)} \underset{\sim}{U}=\left[\begin{array}{llllll}
U_{4,1} & U_{8,1} & U_{12,1} & \cdots & U_{m-8,1} & U_{m-4,1}
\end{array}\right]^{T},
\end{aligned}
$$

and

$$
\underset{\sim}{f}=\left[\begin{array}{llllll}
U_{4,1}+p_{1}^{\prime} U_{01} & U_{8,1} & U_{12,1} & \cdots & U_{m-8,1} & U_{m-4,1}+p_{m-4}^{\prime} \\
U_{m, 1}
\end{array}\right]^{T} .
$$

\section{Analysis of stability}

In this section, the stability analysis on the formulated Caputo's finite-difference approximation in Eq. (6) is considered based on von Neumann's approach and the Lax equivalence theorem $[21,24,33]$.

Theorem 4.1 The fully IFD approximation to the solution of Eq. (1) with $0<\alpha<1$ on the finite domain $0 \leq x \leq 1$, with zero boundary condition $U(0, t)=U(\ell, t)=0$ for all $t \geq 0$, is consistent and unconditionally stable.

Proof Writing the solution of Eq. (1) in the form $U_{j}^{n}=\xi_{n} e^{i \omega j h}, i=\sqrt{-1}, \omega$ is real, Eq. (1) becomes

$$
\begin{gathered}
\sigma_{\alpha, k} \xi_{n-1} e^{i \omega j h}-\sigma_{\alpha, k} \sum_{j=2}^{n} \omega_{j}^{(\alpha)}\left(\xi_{n-j+1} e^{i \omega j h}-\xi_{n-j} e^{i \omega j h}\right) \\
=-p_{i} \xi_{n} e^{i \omega(j-4) h}+\left(\sigma_{\alpha, k}-q_{i}\right) \xi_{n} e^{i \omega j h}-r_{i} \xi_{n} e^{i \omega(j+4) h} .
\end{gathered}
$$

By simplifying and reordering Eq. (10), we get

$$
\sigma_{\alpha, k} \xi_{n-1}-\sigma_{\alpha, k} \sum_{j=2}^{n} \omega_{j}^{(\alpha)}\left(\xi_{n-j+1}-\xi_{n-j}\right)=\xi_{n}\left(\left(\left(-p_{i}-r_{i}\right) \cos (\omega h)\right)+\left(\sigma_{\alpha, k}-q_{i}\right)\right) .
$$

Eventually, from Eq. (11), we reduce to

$$
\xi_{n}=\frac{\xi_{n-1}+\sum_{j=2}^{n} \omega_{j}^{(\alpha)}\left(\xi_{n-j}-\xi_{n-j+1}\right)}{\left(1+\frac{\left(p_{i}+r_{i}\right)}{\sigma_{\alpha, k}} \cos (\omega h)+\frac{q_{i}}{\sigma_{\alpha, k}}\right)}
$$


Hence, from Eq. (12), it can be observed that

$$
\left(1+\frac{\left(-p_{i}-r_{i}\right)}{\sigma_{\alpha, k}} \cos (\omega h)-\frac{q_{i}}{\sigma_{\alpha, k}}\right) \geq 1,
$$

for all $\alpha, n, \omega, h$, and $k$; then we have the inequality $\xi_{1} \leq \xi_{0}$, and

$$
\xi_{n} \leq \xi_{n-1}+\sum_{j=2}^{n} \omega_{j}^{(\alpha)}\left(\xi_{n-j}-\xi_{n-j+1}\right), \quad n \geq 2 .
$$

Based on Eq. (14), for $n=2$, we obtain

$$
\xi_{2} \leq \xi_{1}+\omega_{2}^{(\alpha)}\left(\xi_{0}-\xi_{1}\right)
$$

Then, by repeating the same process as in Eq. (15), we can get

$$
\xi_{j} \leq \xi_{j-1}, \quad j=1,2, \ldots, n-1 .
$$

From Eq. (16), we finally have

$$
\xi_{n} \leq \xi_{n-1}+\sum_{j=2}^{n} \omega_{j}^{(\alpha)}\left(\xi_{n-j}-\xi_{n-j+1}\right) \leq \xi_{n-j} .
$$

Since each term in the sum shown in Eq. (17) is negative, it implies that the inequalities in Eqs. (16) and (17) can be generalized into

$$
\xi_{n} \leq \xi_{n-1} \leq \xi_{n-2} \leq \cdots \leq \xi_{1} \leq \xi_{0} .
$$

Thus, $\xi_{n}=\left|U_{j}^{n}\right| \leq \xi_{0}=\left|U_{j}^{0}\right|=\left|f_{j}\right|$, which entails $\left\|U_{j}^{n}\right\| \leq\left\|f_{j}\right\|$, and we have stability. It follows that the numerical solution of the approximation equation to Eq. (1) converges to the exact solution as $h, k \rightarrow 0$.

\section{QSPAOR iterative method}

In this section, we discuss solving the tridiagonal linear system as in Eq. (9). To formulate the QSPAOR iterative method, first convert the initial linear system into the preconditioned system in the form of

$$
A^{*} \underset{\sim}{x}=f_{\sim}^{*}
$$

Referring to Eq. (19), the new coefficient matrix is obtained by

$$
A^{*}=P A P^{T},
$$

then the right-hand side functional vector is

$$
{\underset{\sim}{f}}^{*}=P f,
$$


and lastly, the approximate solutions are calculated using

$$
\underset{\sim}{U}=P^{T} \underset{\sim}{x}
$$

Based on the transformation that we use in Eqs. (20)-(22), the matrix $P$ is defined as a preconditioning matrix, that is,

$$
P=I+S \text {, }
$$

where

$$
S=\left[\begin{array}{cccccc}
0 & -r_{1}^{\prime} & 0 & 0 & 0 & 0 \\
0 & 0 & -r_{2}^{\prime} & 0 & 0 & 0 \\
0 & 0 & 0 & -r_{3}^{\prime} & 0 & 0 \\
0 & 0 & \ddots & \ddots & \ddots & 0 \\
0 & 0 & 0 & 0 & 0 & -r_{m-1}^{\prime} \\
0 & 0 & 0 & 0 & 0 & 0
\end{array}\right]_{(m-1) \times(m-1)}
$$

and the matrix $I$ is an identity matrix.

Next, we let the coefficient matrix $A^{*}$ in Eq. (19) be given in the form of a sum as follows:

$$
A^{*}=D-L-V \text {. }
$$

Based on the sum of three matrices in Eq. (24), we represent $D, L$, and $V$ as the diagonal, the lower and the upper triangular matrices, respectively. Hence, using the preconditioned system in Eq. (19) and matrices in Eq. (24), the proposed iterative method for solving TFDE, QSPAOR, can be generally formulated as

$$
{\underset{\sim}{x}}^{(K+1)}=(D-\omega L)^{-1}[\beta V+(\beta-\omega) D+(1-\beta) D] \underset{\sim}{\underset{\sim}{(K)}}+\beta(D-\omega L)^{-1}{\underset{\sim}{\sim}}^{*},
$$

where $\underset{\sim}{\underset{\sim}{(K+1)}}$ denotes the vector to be determined at the $(K+1)$ th iteration.

The operation of the QSPAOR method is executed as in Algorithm 1.

\section{Algorithm 1 (QSPAOR method)}

i. Initialize $\underset{\tilde{U}}{U} \leftarrow 0$ and $\varepsilon \leftarrow 10^{-10}$.

ii. For $j=4,8, \ldots, n-4$ and for $i=4,8, \ldots, m-4$, calculate

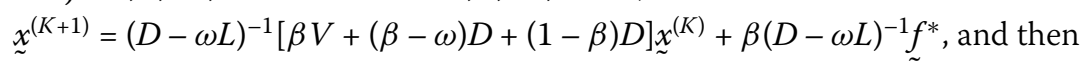
$\underline{\sim}^{(K+1)}=P^{T}{\underset{\sim}{x}}^{(K+1)}$

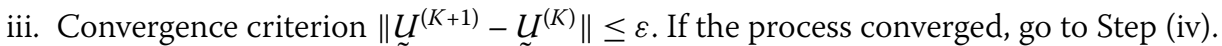
Otherwise, repeat Step (i).

iv. Display approximate solutions.

\section{Convergence of AOR method}

As the QSPAOR iterative method has been formulated, in this section, we discuss the convergence of AOR method that we implement for the solution process to solve Eq. (1). Therefore, let us consider the AOR method [32]:

$$
{\underset{\sim}{x}}^{(K+1)}=(D-\omega L)^{-1}[\beta V+(\beta-\omega) L+(1-\beta) D] \underset{\sim}{x^{(K)}}+\beta(D-\omega L)^{-1}{\underset{\sim}{f}}^{*},
$$


with $n=0,1,2, \ldots$, where

$$
L_{\omega, \beta}=(D-\omega L)^{-1}[(1-\beta) D+(\beta-\omega) L+\beta V]=D-\beta(D-\omega L)^{-1} A .
$$

Theorem 6.1 If the AOR method (16) converges $\left(\rho\left(L_{\omega, \beta}\right)<1\right)$ for some $\beta, \omega \neq 0$, then exactly one of the following statements holds:

(i) $\omega \in(0,2)$ and $\beta \in(-\infty, 0) \cup(0,+\infty)$,

(ii) $\omega \in(-\infty, 0) \cup(2,+\infty)$ and $\beta \in\left(\frac{2 \omega}{(2-\omega)}, 0\right) \cup(0,2)$.

Proof It is known that the eigenvalues $\lambda_{j}$ of $L_{\omega, \beta}(\beta, \omega \neq 0)$ are connected with the eigenvalues $\xi_{j}$ of $L_{\omega, \omega} \equiv L_{\omega}$ ( $L_{\omega}$ is the SOR iteration matrix) by the relationship

$$
\lambda_{j}=\left(1-\frac{\beta}{\omega}\right)+\frac{\beta}{\omega} \xi_{j}, \quad j=2(2) m-2 .
$$

From Eq. (28), we get $\xi_{j}=1-\frac{\omega}{\beta}+\frac{\omega}{\beta} \lambda_{j}, j=2(2) m-2$. We also note that $\prod_{j=2,4, \ldots}^{m-2} \xi_{j}=(1-\omega)^{n}$.

Therefore, $\prod_{j=2,4, \ldots}^{m-2}\left(1-\frac{\omega}{\beta}+\frac{\omega \lambda_{j}}{\beta}\right)-(1-\omega)^{n}$ and since $\left|\lambda_{j}\right|<1, j=2(2) m-2$ from hypothesis, we obtain

$$
\begin{aligned}
\left|(1-\omega)^{n}\right| & =\prod_{j=2,4, \ldots}^{m-2}\left|1-\frac{\omega}{\beta}+\frac{\omega}{\beta} \lambda_{j}\right| \leq \prod_{j=2,4, \ldots}^{m-2}\left(\left|1-\frac{\omega}{\beta}\right|+\left|\frac{\omega}{\beta}\right| \lambda_{j} \mid\right) \\
& <\prod_{j=2,4, \ldots}^{m-2}\left(\left|1-\frac{\omega}{\beta}\right|+\left|\frac{\omega}{\beta}\right|\right)=\left(\left|1-\frac{\omega}{\beta}\right|+\left|\frac{\omega}{\beta}\right|\right)^{n},
\end{aligned}
$$

that is,

$$
|1-\omega|<\left|1-\frac{\omega}{\beta}+\right| \frac{\omega}{\beta}||,
$$

or equivalently,

$$
|\beta(1-\omega)|<|\beta-\omega|+|\omega|
$$

It can be shown that Eq. (31) holds if and only if exactly one of the following statements holds:

(i) $\omega \in(0,2)$ and $\beta \in(-\infty, 0) \cup(0,+\infty)$,

(ii) $\omega \in(-\infty, 0) \cup(2,+\infty)$ and $\beta \in\left(\frac{2 \omega}{(2-\omega)}, 0\right) \cup(0,2)$,

and the proof is completed.

Theorem 6.2 If the AOR method with $\omega=0$ converges $\left(\rho\left(L_{0, \beta}\right)<1\right)$ then $0<\beta<2$.

Proof If $\omega=0$, then $L_{0, \beta}=(1-\beta) D+\beta(L+U)=(1-\beta) D+\beta B$. If $\mu_{j}, j=2(2) m-2$ are the eigenvalues of $B$, then for the eigenvalues $\lambda_{j}$ of $L_{0, \beta}$ we get

$$
\lambda_{j}=1-\beta+\beta \mu_{j}, \quad j=2(2) m-2,
$$


which implies

$$
\mu_{j}=\frac{1}{\beta}\left(\beta-1+\lambda_{j}\right), \quad j=2(2) m-2 .
$$

But since $B=0$, we get

$$
\sum_{j=2,4, \ldots}^{m-2} \mu_{j}=0=\sum_{j=2,4, \ldots}^{m-2} \frac{1}{\beta}\left(\beta-1+\lambda_{j}\right) .
$$

From Eq. (34) we have

$$
\sum_{j=2,4, \ldots}^{m-2} \lambda_{j}=\left(\frac{m}{2}-1\right) \cdot(1-\beta)
$$

and consequently,

$$
\left|\left(\frac{m}{2}-1\right)(1-\beta)\right|=\left|\sum_{j=2,4, \ldots}^{m-2} \lambda_{j}\right| \leq \sum_{j=2,4, \ldots}^{m-2}\left|\lambda_{j}<n\right| .
$$

Since $\left|\lambda_{j}\right|<1, j=2(2) m-2$ from the hypothesis, $\left|\left(\frac{m}{2}-1\right)(1-\beta)\right|<n$, or $0<\beta<2$.

\section{Time-fractional diffusion examples}

For the numerical simulation, we consider two examples of the TFDE problems to evaluate the efficiency of the proposed QSPAOR against the previously developed iterative methods in our research, namely HSPAOR and FSPAOR. The three criteria, as mentioned in Sect. 2, are compared for each of the three different values of $\alpha$, i.e., $\alpha=0.25, \alpha=0.50$, and $\alpha=0.75$. The iteration cycle for the running program based on Algorithm 1 is limited by the tolerance $\varepsilon=10^{-10}$. We consider the following two TFDE examples, namely the time-fractional initial boundary value problems from [6]:

\section{Example 1}

$$
\frac{\partial^{\alpha} U(x, t)}{\partial t^{\alpha}}=\frac{\partial^{2} U(x, t)}{\partial x^{2}}, \quad 0<\alpha \leq 1,0 \leq x \leq \gamma, t>0 .
$$

The boundary conditions that we implement are stated in fractional terms as follows:

$$
U(0, t)=\frac{2 k t^{\alpha}}{\Gamma(\alpha+1)}, \quad U(\ell, t)=\ell^{2}+\frac{2 k t^{\alpha}}{\Gamma(\alpha+1)},
$$

and to initiate the approximate solutions, we set the initial condition

$$
U(x, 0)=x^{2} .
$$

Example 2

$$
\frac{\partial U(x, t)}{\partial t}=\Gamma(1.2) x^{\beta} \frac{\partial^{\beta} U(x, t)}{\partial x^{\beta}}+3 x^{2}(2 x-1) e^{-t} .
$$


Table 1 Numerical results for Example 1

\begin{tabular}{|c|c|c|c|c|c|c|c|c|c|c|}
\hline \multirow[t]{2}{*}{$\bar{M}$} & \multirow[t]{2}{*}{ Method } & \multicolumn{3}{|l|}{$\alpha=0.25$} & \multicolumn{3}{|l|}{$\alpha=0.50$} & \multicolumn{3}{|c|}{$\alpha=0.75$} \\
\hline & & $\bar{K}$ & Seconds & MAE & $\bar{K}$ & Seconds & MAE & $\bar{K}$ & Seconds & MAE \\
\hline 128 & $\begin{array}{l}\text { FSPAOR } \\
\text { HSPAOR } \\
\text { QSPAOR }\end{array}$ & $\begin{array}{r}1351 \\
409 \\
200\end{array}$ & $\begin{array}{l}5.80 \\
2.47 \\
0.92\end{array}$ & $\begin{array}{l}9.97 e-05 \\
9.97 e-05 \\
9.96 e-05\end{array}$ & $\begin{array}{l}694 \\
253 \\
124\end{array}$ & $\begin{array}{l}0.92 \\
0.46 \\
0.24\end{array}$ & $\begin{array}{l}9.86 e-05 \\
9.85 e-05 \\
9.84 e-05\end{array}$ & $\begin{array}{r}318 \\
93 \\
44\end{array}$ & $\begin{array}{l}0.37 \\
0.12 \\
0.07\end{array}$ & $\begin{array}{l}1.30 \mathrm{e}-04 \\
1.30 \mathrm{e}-04 \\
1.29 \mathrm{e}-04\end{array}$ \\
\hline 256 & $\begin{array}{l}\text { FSPAOR } \\
\text { HSPAOR } \\
\text { QSPAOR }\end{array}$ & $\begin{array}{r}4192 \\
1605 \\
784\end{array}$ & $\begin{array}{r}24.95 \\
11.00 \\
4.19\end{array}$ & $\begin{array}{l}9.97 e-05 \\
9.97 e-05 \\
9.95 e-05\end{array}$ & $\begin{array}{r}2694 \\
1027 \\
502\end{array}$ & $\begin{array}{l}7.52 \\
4.47 \\
2.10\end{array}$ & $\begin{array}{l}9.90 e-05 \\
9.89 e-05 \\
9.88 e-05\end{array}$ & $\begin{array}{r}1307 \\
492 \\
241\end{array}$ & $\begin{array}{l}2.92 \\
1.46 \\
0.87\end{array}$ & $\begin{array}{l}1.30 \mathrm{e}-04 \\
1.29 \mathrm{e}-04 \\
1.28 \mathrm{e}-04\end{array}$ \\
\hline 512 & $\begin{array}{l}\text { FSPAOR } \\
\text { HSPAOR } \\
\text { QSPAOR }\end{array}$ & $\begin{array}{r}15,608 \\
6029 \\
2950\end{array}$ & $\begin{array}{r}236.25 \\
114.76 \\
43.02\end{array}$ & $\begin{array}{l}9.99 e-05 \\
9.97 e-05 \\
9.95 e-05\end{array}$ & $\begin{array}{r}10,085 \\
3887 \\
1540\end{array}$ & $\begin{array}{l}62.59 \\
32.61 \\
15.21\end{array}$ & $\begin{array}{l}9.90 e-05 \\
9.90 e-05 \\
9.89 e-05\end{array}$ & $\begin{array}{r}4947 \\
1900 \\
928\end{array}$ & $\begin{array}{r}29.56 \\
15.05 \\
7.21\end{array}$ & $\begin{array}{l}1.32 \mathrm{e}-04 \\
1.31 \mathrm{e}-04 \\
1.30 \mathrm{e}-04\end{array}$ \\
\hline 1024 & $\begin{array}{l}\text { FSPAOR } \\
\text { HSPAOR } \\
\text { QSPAOR }\end{array}$ & $\begin{array}{l}54,130 \\
21,478 \\
10,640\end{array}$ & $\begin{array}{r}3378.36 \\
1613.83 \\
898.67\end{array}$ & $\begin{array}{l}9.99 e-05 \\
9.97 e-05 \\
9.95 e-05\end{array}$ & $\begin{array}{r}33,652 \\
13,387 \\
5531\end{array}$ & $\begin{array}{l}432.78 \\
212.95 \\
103.96\end{array}$ & $\begin{array}{l}9.90 e-05 \\
9.88 e-05 \\
9.87 e-05\end{array}$ & $\begin{array}{r}16,609 \\
6498 \\
3479\end{array}$ & $\begin{array}{r}215.41 \\
113.40 \\
53.67\end{array}$ & $\begin{array}{l}1.40 \mathrm{e}-04 \\
1.40 \mathrm{e}-04 \\
1.39 \mathrm{e}-04\end{array}$ \\
\hline 2048 & $\begin{array}{l}\text { FSPAOR } \\
\text { HSPAOR } \\
\text { QSPAOR }\end{array}$ & $\begin{array}{r}196,523 \\
77,153 \\
38,471\end{array}$ & $\begin{array}{r}14,378.36 \\
7189.71 \\
3078.90\end{array}$ & $\begin{array}{l}9.99 \mathrm{e}-05 \\
9.97 \mathrm{e}-05 \\
9.96 \mathrm{e}-05\end{array}$ & $\begin{array}{r}121,947 \\
47,933 \\
19,711\end{array}$ & $\begin{array}{r}3026.56 \\
1349.79 \\
601.76\end{array}$ & $\begin{array}{l}9.90 e-05 \\
9.90 e-05 \\
9.88 e-05\end{array}$ & $\begin{array}{l}59,500 \\
23,344 \\
11,740\end{array}$ & $\begin{array}{r}1211.32 \\
694.40 \\
321.85\end{array}$ & $\begin{array}{l}1.71 \mathrm{e}-04 \\
1.71 \mathrm{e}-04 \\
1.70 \mathrm{e}-04\end{array}$ \\
\hline
\end{tabular}

Table 2 Numerical results for Example 2

\begin{tabular}{|c|c|c|c|c|c|c|c|c|c|c|}
\hline \multirow[t]{2}{*}{$\bar{M}$} & \multirow[t]{2}{*}{ Method } & \multicolumn{3}{|c|}{$\alpha=0.25$} & \multicolumn{3}{|c|}{$\alpha=0.50$} & \multicolumn{3}{|c|}{$\alpha=0.75$} \\
\hline & & $\bar{K}$ & Seconds & MAE & $\bar{K}$ & Seconds & MAE & $\bar{K}$ & Seconds & MAE \\
\hline 128 & $\begin{array}{l}\text { FSPAOR } \\
\text { HSPAOR } \\
\text { QSPAOR }\end{array}$ & $\begin{array}{r}406 \\
136 \\
49\end{array}$ & $\begin{array}{l}3.32 \\
1.48 \\
0.72\end{array}$ & $\begin{array}{l}1.95 \mathrm{e}-02 \\
1.94 \mathrm{e}-02 \\
1.94 \mathrm{e}-02\end{array}$ & $\begin{array}{r}153 \\
77 \\
34\end{array}$ & $\begin{array}{l}2.27 \\
1.30 \\
0.64\end{array}$ & $\begin{array}{l}8.29 \mathrm{e}-02 \\
8.30 \mathrm{e}-02 \\
8.29 \mathrm{e}-02\end{array}$ & $\begin{array}{r}142 \\
71 \\
19\end{array}$ & $\begin{array}{l}1.62 \\
0.67 \\
0.33\end{array}$ & $\begin{array}{l}1.37 \mathrm{e}-01 \\
1.36 \mathrm{e}-01 \\
1.35 \mathrm{e}-01\end{array}$ \\
\hline 256 & $\begin{array}{l}\text { FSPAOR } \\
\text { HSPAOR } \\
\text { QSPAOR }\end{array}$ & $\begin{array}{r}1270 \\
618 \\
270\end{array}$ & $\begin{array}{r}14.75 \\
7.21 \\
3.35\end{array}$ & $\begin{array}{l}1.95 \mathrm{e}-02 \\
1.94 \mathrm{e}-02 \\
1.94 \mathrm{e}-02\end{array}$ & $\begin{array}{l}591 \\
287 \\
141\end{array}$ & $\begin{array}{l}8.21 \\
4.33 \\
2.03\end{array}$ & $\begin{array}{l}8.29 e-02 \\
8.30 e-02 \\
8.29 e-02\end{array}$ & $\begin{array}{r}236 \\
111 \\
81\end{array}$ & $\begin{array}{l}4.28 \\
2.33 \\
1.96\end{array}$ & $\begin{array}{l}1.37 \mathrm{e}-01 \\
1.36 \mathrm{e}-01 \\
1.35 \mathrm{e}-01\end{array}$ \\
\hline 512 & $\begin{array}{l}\text { FSPAOR } \\
\text { HSPAOR } \\
\text { QSPAOR }\end{array}$ & $\begin{array}{l}4841 \\
2365 \\
1044\end{array}$ & $\begin{array}{l}91.72 \\
44.07 \\
21.10\end{array}$ & $\begin{array}{l}1.95 \mathrm{e}-02 \\
1.95 \mathrm{e}-02 \\
1.94 \mathrm{e}-02\end{array}$ & $\begin{array}{r}2330 \\
1139 \\
592\end{array}$ & $\begin{array}{l}53.97 \\
23.24 \\
11.87\end{array}$ & $\begin{array}{l}8.29 e-02 \\
8.30 e-02 \\
8.29 e-02\end{array}$ & $\begin{array}{r}1064 \\
519 \\
324\end{array}$ & $\begin{array}{r}31.84 \\
12.77 \\
5.25\end{array}$ & $\begin{array}{l}1.37 \mathrm{e}-01 \\
1.36 \mathrm{e}-01 \\
1.35 \mathrm{e}-01\end{array}$ \\
\hline 1024 & $\begin{array}{l}\text { FSPAOR } \\
\text { HSPAOR } \\
\text { QSPAOR }\end{array}$ & $\begin{array}{r}16,373 \\
8816 \\
3908\end{array}$ & $\begin{array}{r}152.97 \\
61.07 \\
29.58\end{array}$ & $\begin{array}{l}1.94 \mathrm{e}-02 \\
1.94 \mathrm{e}-02 \\
1.94 \mathrm{e}-02\end{array}$ & $\begin{array}{l}8471 \\
4273 \\
1895\end{array}$ & $\begin{array}{l}428.76 \\
213.24 \\
106.90\end{array}$ & $\begin{array}{l}8.29 e-02 \\
8.30 e-02 \\
8.29 e-02\end{array}$ & $\begin{array}{l}4029 \\
1987 \\
1219\end{array}$ & $\begin{array}{r}323.97 \\
148.63 \\
51.76\end{array}$ & $\begin{array}{l}1.37 \mathrm{e}-01 \\
1.36 \mathrm{e}-01 \\
1.35 \mathrm{e}-01\end{array}$ \\
\hline 2048 & $\begin{array}{l}\text { FSPAOR } \\
\text { HSPAOR } \\
\text { QSPAOR }\end{array}$ & $\begin{array}{l}59,608 \\
29,771 \\
13,203\end{array}$ & $\begin{array}{l}853.87 \\
426.83 \\
209.50\end{array}$ & $\begin{array}{l}1.94 \mathrm{e}-02 \\
1.95 \mathrm{e}-02 \\
1.94 \mathrm{e}-02\end{array}$ & $\begin{array}{r}31,048 \\
15,340 \\
6852\end{array}$ & $\begin{array}{r}1121.34 \\
511.24 \\
251.99\end{array}$ & $\begin{array}{l}8.29 \mathrm{e}-02 \\
8.30 \mathrm{e}-02 \\
8.29 \mathrm{e}-02\end{array}$ & $\begin{array}{r}14,899 \\
7344 \\
4497\end{array}$ & $\begin{array}{l}614.63 \\
253.97 \\
123.18\end{array}$ & $\begin{array}{l}1.37 \mathrm{e}-01 \\
1.36 \mathrm{e}-01 \\
1.35 \mathrm{e}-01\end{array}$ \\
\hline
\end{tabular}

For the example of Eq. (40), we initiate the approximate solutions using the initial condition $U(x, 0)=x^{2}-x^{3}$ and implement the zero Dirichlet conditions. Meanwhile, the exact solution to this problem is $U(x, t)=x^{2}(1-x) e^{-t}$.

All-important numerical results from the implementation of QSPAOR, HSPAOR, and FSPAOR methods to solve the numerical examples in Eqs. (37) and (40) are recorded in Tables 1 and 2. For the consistency inspection, we run the numerical simulation by increasing the values of mesh sizes, that is, $m=128,256,512,1024$, and 2048. Based on the results tabulated in Tables 1 and 2, we found that QSPAOR required the least number of iterations and the shortest computation time to finish computing the two examples' solutions compared to the HSPAOR and FSPAOR. The numerical results are similar for all values of mesh sizes and parameter $\alpha$. These results attribute the significant improvement in computing efficiency to the quarter-sweep technique, which computes a quarter 
of the total number of mesh points using PAOR instead of all mesh points in the solution domain.

The results can be summarized as follows. For Example 1, the number of iterations and computation time have declined by $80.25-85.36 \%$ and $71.89-81.78 \%$, respectively, if QSPAOR method is compared to the FSPAOR method. When QSPAOR is compared to HSPAOR, the number of iterations and the computation time have reduced by about 49.20-54.74\% and 44.18-57.27\%, respectively. For Example 2, QSPAOR has reduced the number of iterations and the computation time of FSPAOR by about $72.13-84.16 \%$ and 67.16-80.90\% respectively. When compared to HSPAOR, these improvements became $43.57-64.35 \%$ and $38.57-57.28 \%$, respectively. Overall, the accuracy of the three numerical methods, i.e., QSPAOR, HSPAOR, and FSPAOR, is comparable.

\section{Conclusion}

This paper solved a one-dimensional TFDE by applying the quarter-sweep finite-difference scheme and the PAOR iterative method. Using the quarter-sweep technique and PAOR iterative method, the computational complexity of computing the solutions of the TFDE has been successfully reduced. The quarter-sweep calculated only a quarter of the total mesh points by using PAOR while averaging the remaining mesh points, and the result is promising. The numerical experiments demonstrated the efficiency of the proposed QSPAOR method, in which the number of iterations and computation time have been reduced significantly, compared to the HSPAOR and FSPAOR methods. In addition to that, the accuracy of the three tested methods is almost identical. The study found that the computational complexity reduction by the quarter-sweep and the PAOR method can be an efficient numerical method to solve TFDE.

Acknowledgements

The authors would like to thank the anonymous referees and the handling editor for their careful reading and relevant remarks/suggestions.

Funding

The author(s) received no financial support for the research, authorship, and/or publication of this article.

Availability of data and materials

Not applicable.

Competing interests

The authors declare that they have no competing interests.

Authors' contributions

The authors contributed equally to this article. They have all read and approved the final manuscript.

Author details

1Department Tadris Matematika, IAIN Bengkulu, Bengkulu City, Bengkulu, 65144, Indonesia. ²Department Mathematics, Anand International College of Engineering, Near Kanota, Agra Road, Jaipur, Rajasthan, 303012, India. ${ }^{3}$ Nonlinear Dynamics Research Center (NDRC), Ajman University, Ajman, UAE. ${ }^{4}$ Faculty of Science and Natural Resources, Universiti Malaysia Sabah, Kota Kinabalu, Sabah, 88400, Malaysia. ${ }^{5}$ Faculty of Computing and Informatics, Universiti Malaysia Sabah Labuan International Campus, Labuan F.T., 87000, Malaysia. ${ }^{6}$ Institute of Mathematical Sciences, University of Malaya, Kuala Lumpur, 50603, Malaysia.

\section{Publisher's Note}

Springer Nature remains neutral with regard to jurisdictional claims in published maps and institutional affiliations.

Received: 1 December 2020 Accepted: 18 February 2021 Published online: 02 March 2021

References

1. Agarwal, P., El-Sayed, A.A.: Vieta-Lucas polynomials for solving a fractional-order mathematical physics model. Adv. Differ. Equ. 2020(1), 626 (2020). https://doi.org/10.1186/s13662-020-03085-y 
2. Akram, T., Abbas, M., Ali, A., Iqbal, A., Baleanu, D.: A numerical approach of a time fractional reaction-diffusion model with a non-singular kernel. Symmetry 12(10), 1653 (2020). https://doi.org/10.3390/sym12101653

3. Ali, K.K., Osman, M.S., Baskonus, H.M., Elazabb, N.S., Ilhan, E.: Analytical and numerical study of the HIV-1 infection of CD4+ T-cells conformable fractional mathematical model that causes acquired immunodeficiency syndrome with the effect of antiviral drug therapy. Math. Methods Appl. Sci. (2020). https://doi.org/10.1002/mma.7022

4. Aruchunan, E., Muthuvalu, M.S., Sulaiman, J.: Quarter-sweep iteration concept on conjugate gradient normal residual method via second order quadrature-finite difference schemes for solving Fredholm integro-differential equations. Sains Malays. 44(1), 139-146 (2015). https://doi.org/10.17576/jsm-2015-4401-19

5. Cen, Z., Huang, J., Le, A., Xu, A.: A second-order scheme for a time-fractional diffusion equation. Appl. Math. Lett. 90, 79-85 (2019). https://doi.org/10.1016/j.aml.2018.10.016

6. Demir, A., Erman, S., Özgür, B., Korkmaz, E.: Analysis of fractional partial differential equations by Taylor series expansion. Bound. Value Probl. 2013(1), 68 (2013). https://doi.org/10.1186/1687-2770-2013-68

7. Duo, S., Ju, L., Zhang, Y.: A fast algorithm for solving the space-time fractional diffusion equation. Comput. Math. Appl. 75(6), 1929-1941 (2018). https://doi.org/10.1016/j.camwa.2017.04.008

8. Fujita, Y.: Cauchy problems of fractional order and stable processes. Jpn. J. Appl. Math. 7(3), 459-476 (1990). https://doi.org/10.1007/bf03167854

9. Gao, W., Veeresha, P., Prakasha, D.G., Baskonus, H.M.: New numerical simulation for fractional Benney-Lin equation arising in falling film problems using two novel techniques. Numer. Methods Partial Differ. Equ. 37(1), 210-243 (2021). https://doi.org/10.1002/num.22526

10. Gao, W., Veeresha, P., Prakasha, D.G., Baskonus, H.M., Yel, G.: New numerical results for the time-fractional Phi-four equation using a novel analytical approach. Symmetry 12(3), 478 (2020). https://doi.org/10.3390/sym1 2030478

11. Gao, W., Yel, G., Baskonus, H.M., Cattani, C.: Complex solitons in the conformable (2+1)-dimensional Ablowitz-Kaup-Newell-Segur equation. AIMS Math. 5(1), 507-521 (2020). https://doi.org/10.3934/math.2020034

12. Garrappa, R.: Numerical solution of fractional differential equations: a survey and a software tutorial. Mathematics 6(2), 16 (2018). https://doi.org/10.3390/math6020016

13. Gong, C., Bao, W., Tang, G., Jiang, Y., Liu, J.: Computational challenge of fractional differential equations and the potential solutions: a survey. Math. Probl. Eng. 2015, 258265 (2015). https://doi.org/10.1155/2015/258265

14. González-Olvera, M.A., Torres, L., Hernández-Fontes, J.V., Mendoza, E.: Time fractional diffusion equation for shipping water events simulation. Chaos Solitons Fractals 143, 110538 (2021). https://doi.org/10.1016/j.chaos.2020.110538

15. Gunawardena, A.D., Jain, S.K., Snyder, L.: Modified iterative methods for consistent linear systems. Linear Algebra Appl. 154-156, 123-143 (1991). https://doi.org/10.1016/0024-3795(91)90376-8

16. Hacksbusch, W.: Iterative solution of large sparse systems of equations. Appl. Math. Sci. (1994). https://doi.org/10.1007/978-1-4612-4288-8

17. Hilfer, R.: Foundations of fractional dynamics. Fractals 3(3), 549-556 (1995). https://doi.org/10.1142/s0218348x95000485

18. Hilfer, R.: Fractional diffusion based on Riemann-Liouville fractional derivatives. J. Phys. Chem. B 104(16), 3914-3917 (2000). https://doi.org/10.1021/jp9936289

19. Jaradat, I., Alquran, M., Momani, S., Baleanu, D.: Numerical schemes for studying biomathematics model inherited with memory-time and delay-time. Alex. Eng. J. 59(5), 2969-2974 (2020). https://doi.org/10.1016/j.aej.2020.03.038

20. Kumar, S., Shaw, P.K., Abdel-Aty, A., Mahmoud, E.E.: A numerical study on fractional differential equation with population growth model. Numer. Methods Partial Differ. Equ. (2020). https://doi.org/10.1002/num.22684

21. Langlands, T.A.M., Henry, B.I.: The accuracy and stability of an implicit solution method for the fractional diffusion equation. J. Comput. Phys. 205(2), 719-736 (2005). https://doi.org/10.1016/j.jcp.2004.11.025

22. Othman, M., Abdullah, A.R.: An efficient four points modified explicit group Poisson solver. Int. J. Comput. Math. 76(2), 203-217 (2000). https://doi.org/10.1080/00207160008805020

23. Saad, Y.: Iterative Methods for Sparse Linear Systems. SIAM, Philadelphia (2003)

24. Schultz, M.H.: A generalization of the Lax equivalence theorem. Proc. Am. Math. Soc. 17(5), 1034-1035 (1966). https://doi.org/10.1090/s0002-9939-1966-0198262-1

25. Sun, H., Cao, W.: A fast temporal second-order difference scheme for the time-fractional subdiffusion equation. Numer. Methods Partial Differ. Equ. (2020). https://doi.org/10.1002/num.22612

26. Sunarto, A., Sulaiman, J.: Computational algorithm PAOR for time-fractional diffusion equations. IOP Conf. Ser., Mater. Sci. Eng. 874, 012029 (2020). https://doi.org/10.1088/1757-899x/874/1/012029

27. Veeresha, P., Baskonus, H.M., Prakasha, D.G., Gao, W., Yel, G.: Regarding new numerical solution of fractional Schistosomiasis disease arising in biological phenomena. Chaos Solitons Fractals 133, 109661 (2020). https://doi.org/10.1016/j.chaos.2020.109661

28. Vui Lung, J.C., Sulaiman, J.: On quarter-sweep finite difference scheme for one-dimensional porous medium equations. Int. J. Appl. Math. 33(3), 439-450 (2020). https://doi.org/10.12732/ijam.v33i3.6

29. $\mathrm{Xu}, \mathrm{Q} ., \mathrm{Xu}, \mathrm{Y}$.: Extremely low order time-fractional differential equation and application in combustion process. Commun. Nonlinear Sci. Numer. Simul. 64, 135-148 (2018). https://doi.org/10.1016/j.cnsns.2018.04.021

30. Yang, X.J., Gao, F.: A new technology for solving diffusion and heat equations. Therm. Sci. 21(1 Part A), 133-140 (2017). https://doi.org/10.2298/tsci160411246y

31. Yang, X.J., Ragulskis, M., Taha, T: A new general fractional-order derivative with Rabotnov fractional-exponential kernel. Therm. Sci. 23(6 Part B), 3711-3718 (2019). https://doi.org/10.2298/tsci180825254y

32. Yeyios, A.K.: A necessary condition for the convergence of the accelerated overrelaxation (AOR) method. J. Comput. Appl. Math. 26(3), 371-373 (1989). https://doi.org/10.1016/0377-0427(89)90309-9

33. Zwillinger, D.: Handbook of Differential Equations, 3rd edn. Academic Press, San Diego (1997) 